\title{
Short- and long-term effects of diving on pulmonary function
}

\author{
Kay Tetzlaff ${ }^{1}$ and Paul S. Thomas ${ }^{2,3}$ \\ Number 6 in the Series "Sports-related lung disease" \\ Edited by Yochai Adir and Alfred A. Bove
}

\begin{abstract}
Affiliations: ${ }^{1}$ Dept of Sports Medicine, Medical Clinic, Eberhard-Karls-University of Tübingen, Tübingen, Germany. ${ }^{2}$ Faculty of Medicine, University of New South Wales, Sydney, Australia. ${ }^{3}$ Dept of Respiratory Medicine, Prince of Wales Hospital, Randwick, Australia.
\end{abstract}

Correspondence: Kay Tetzlaff, Dept of Sports Medicine, Medical Clinic, Eberhard-Karls-University of Tübingen, Hoppe-Seyler-Str. 6, 72076 Tübingen, Germany. E-mail: Kay.tetzlaffaklinikum.uni-tuebingen.de

@ERSpublications

The effects of diving on pulmonary function largely depend on factors associated with the individual diving response http://ow.ly/aIFS3095WNn

Cite this article as: Tetzlaff K, Thomas PS. Short- and long-term effects of diving on pulmonary function. Eur Respir Rev 2017; 26: 160097 [https://doi.org/10.1183/16000617.0097-2016].

ABSTRACT The diving environment provides a challenge to the lung, including exposure to high ambient pressure, altered gas characteristics and cardiovascular effects on the pulmonary circulation. Several factors associated with diving affect pulmonary function acutely and can potentially cause prolonged effects that may accumulate gradually with repeated diving exposure. Evidence from experimental deep dives and longitudinal studies suggests long-term adverse effects of diving on the lungs in commercial deep divers, such as the development of small airways disease and accelerated loss of lung function. In addition, there is an accumulating body of evidence that diving with self-contained underwater breathing apparatus (scuba) may not be associated with deleterious effects on pulmonary function. Although changes in pulmonary function after single scuba dives have been found to be associated with immersion, ambient cold temperatures and decompression stress, changes in lung function were small and suggest a low likelihood of clinical significance. Recent evidence points to no accelerated loss of lung function in military or recreational scuba divers over time. Thus, the impact of diving on pulmonary function largely depends on factors associated with the individual diving exposure. However, in susceptible subjects clinically relevant worsening of lung function may occur even after single shallow-water scuba dives.

\section{Introduction}

The human respiratory system has adapted to breathing air at sea level, i.e. atmospheric pressure, which varies smoothly around $101 \mathrm{kPa}$. However, diving comprises exposure to distinct environmental conditions that challenge the respiratory system beyond normal physiology [1], e.g. elevated ambient pressure and

Previous articles in this series: No. 1: Adir Y, Bove AA. Can asthmatic subjects dive? Eur Respir Rev 2016; 25: 214-220. No. 2: Szpilman D, Orlowski JP. Sports related to drowning. Eur Respir Rev 2016; 25: 348-359. No. 3: van Ooij PJAM, Sterk PJ, van Hulst RA. Oxygen, the lung and the diver: friends and foes? Eur Respir Rev 2016; 25: $496-$ 505. No. 4: Mijacika T, Dujic Z. Sports-related lung injury during breath-hold diving. Eur Respir Rev 2016; 25: 506-512. No. 5: Luks AM, Swenson ER, Bärtsch P. Acute high-altitude sickness. Eur Respir Rev 2017; 26: 160096.

Received: Sept 142016 | Accepted after revision: Feb 082017

Conflict of interest: None declared.

Provenance: Submitted article, peer reviewed.

Copyright OERS 2017. ERR articles are open access and distributed under the terms of the Creative Commons Attribution Non-Commercial Licence 4.0. 
altered gas characteristics. Several factors associated with diving exposure may affect the respiratory system. Table 1 summarises environmental conditions associated with diving and their possible (patho-) physiological impact on the lungs and airways. These conditions may be present alone or in combination, and their effects on pulmonary function may overlap, due to the particular diving exposure.

Diving encompasses heterogeneous activities with regards to the diving environment. Breath-hold diving exposes the body to immersion and hydrostatic pressure, and the exposure is limited by breath-hold duration. Diving with breathing support may utilise gas supply through self-contained underwater breathing apparatus (scuba) or by surface- or underwater habitat-based supply systems that deliver the breathing gas through pressure hoses to diver's helmet or mask. Scuba diving is by far the most commonly practised exposure in recreational diving, with air being the usual breathing gas. Other breathing gases are available, such as enriched air nitrox which includes nitrogen-oxygen mixtures with proportions of oxygen exceeding $21 \%$, or pure oxygen, and these will exert distinct effects on the respiratory system. In technical diving, different breathing gases are used during the same dive, and inert gases other than nitrogen may be used to reach greater depths. Saturation diving techniques, which entail equilibration of body tissues with gas mixtures breathed at depths as shallow as $20 \mathrm{~m}$ of seawater are still employed in commercial diving.

Commercial diving exposure, in particular saturation diving, may lead to long-term detrimental effects on the respiratory system [2-4], but there remains some controversy with regard to possible long-term injury to the lungs from scuba diving. Only more recently have studies investigated pulmonary function changes in recreational scuba divers and special populations such as adolescents and subjects with asthma or atopy. This article reviews the current literature evidence regarding the short- and long-term effects of diving on pulmonary function, with an emphasis on scuba diving. The studies reviewed were derived from the subject headings from PubMed, as detailed below.

\section{Diving exposure}

The diving environment is distinct from life at sea level with regards to a higher ambient pressure, since hydrostatic pressure increasingly adds to atmospheric pressure with diving depth. For example, ambient pressure at $10 \mathrm{~m}$ of seawater depth is twice the pressure at sea level, i.e. $\sim 200 \mathrm{kPa}$. While the human lungs can withstand very high ambient pressure per se, it is the change in characteristics of the inspired gas under pressure that challenges the respiratory system.

TABLE 1 Conditions associated with diving exposure and their impact on the physiology of the respiratory system and possibly resulting adverse clinical consequences

Pathophysiological changes

Possible adverse clinical effects

$\begin{array}{lll}\begin{array}{ll}\text { Elevated pressure } \\ \text { Oxygen }\end{array} & \text { Hyperoxia } & \text { Oxidative stress } \\ \text { Nitrogen } & \text { Venous gas microbubbles } & \text { Airway inflammation } \\ & & \text { Impaired diffusion capacity } \\ \text { Immersion } & \text { Central blood pooling } & \text { Pulmonary hypertension } \\ & \text { Reduced lung compliance } & \text { Dyspnoea } \\ \text { Increased work of breathing } & \\ \text { Scuba } & \text { Dry and cold gas } & \\ \text { Breathing gas } & \text { Increased density of gas } & \\ & \text { Increased airway resistance } & \text { Respiratory heat loss } \\ & \text { Increased work of breathing } & \text { Airway inflammation } \\ \text { Pressure regulator } & \text { Airway narrowing } \\ & \text { Dyspnoea } \\ \text { Exertion } & \text { Dyspnoea } \\ & \text { Increased work of breathing } & \text { Aggravation of airway drying and cooling when } \\ & & \text { bypassing nasal airways } \\ & & \text { Dyspnoea } \\ & & \text { Carbon dioxide retention } \\ \text { Water } & \text { Exercise-induced bronchoconstriction } \\ & & \text { Capillary stress failure }\end{array}$

${ }^{\#}$ : when diving using a mask and breathing through a regulator. 
With breath-hold diving, total lung volume will decrease with increasing depth or ambient pressure, due to Boyle's law. The pressure and density of the gas inside the lungs will increase accordingly. Since, theoretically, the human lung will only collapse completely at depths $>200 \mathrm{~m}$ [5], gas exchange through the alveolar capillary interface will not cease up to that depth and, thus, nitrogen will diffuse along the alveolar-tissue pressure gradient to become dissolved in tissues during descent. Alveolar oxygen pressure will continue to increase with descent and so will arterial oxygen pressure, while alveolar carbon dioxide pressure will only increase to a minor degree, as large amounts of this highly soluble gas are taken up by the increased thoracic blood volume.

In scuba diving, the respired gas is compressed in a cylinder and inspired via a pressure reducer and a regulator integrated into a full-face mask or, most commonly, attached to a mouthpiece. The regulator reduces the cylinder high gas pressure to ambient pressure and supplies gas on demand. The compressed gas needs to be dry to prevent ice formation in the pressure regulators. At depth, the inspired gas will be delivered at ambient pressure, i.e. ventilatory volumes will be comparable to sea level, but the gas will be dense. For example, at a depth of $30 \mathrm{~m}$, the regulator supplies air at four times the pressure at sea level; the density of air will be four times higher than breathing air at sea level. Inspiratory resistive loading and dead space from scuba equipment add to the work of breathing under water. Variations in posture may alter these values, and the work of breathing also increases and varies with posture.

Gases physiologic to humans at sea level can become harmful at depth. In the case of breathing air, a gas mixture mainly composed of nitrogen (78\%) and oxygen (21\%), with traces of water vapour, carbon dioxide and other gases, the partial pressure of oxygen will increase with depth. Breathing air at a depth of $40 \mathrm{~m}$ will mean that the arterial oxygen partial pressure is roughly equivalent to breathing $100 \%$ oxygen at the surface. Unlike oxygen, nitrogen as an inert gas is not metabolised. At increased pressure, nitrogen will exert narcotic effects. In addition, during descent (compression), nitrogen molecules will diffuse into body tissues where nitrogen partial pressures are below ambient nitrogen pressure. This tissue saturation with nitrogen is predominantly determined by depth and time at depth, while specific tissue saturation kinetics also apply. Upon ascent (decompression), diffusion will reverse and tissue nitrogen pressure will exceed alveolar nitrogen pressure. Nitrogen gas microbubbles may evolve from pre-existing gas nuclei and will transfer from tissues with the venous return to the lung microvasculature where they are filtered in capillaries, and nitrogen will diffuse into the alveolar space. These inert gas microemboli may exert inflammatory stress upon the lung microvasculature [6].

Factors unrelated to pressure and breathing gas provide additional respiratory effects of diving: water immersion poses changes on the cardiovascular system, with central pooling of blood in the chest cavity and cranial shift of the diaphragm. Respiratory effects that have been measured during head-out immersion in thermoneutral water include a decrease in lung volumes and an increase in airway resistance, while lung compliance decreases $[7,8]$. An increase in diffusing capacity has been shown to be due to vascular engorgement [9]. Cold water immersion may lead to marked respiratory changes, such as hyperventilation and hypocapnia through neurogenic mechanisms [10]. Even at comfortable water temperatures, greater thermal conduction and convection of water versus air accelerate heat loss and may cause peripheral vasoconstriction. Scuba equipment, wetsuits and weight belts add to the restrictive forces on the chest wall and abdomen, which may be further aggravated if equipment is excessively tight fitting. These factors impair the compliance of the chest wall and impede diaphragmatic breathing.

The combination of these conditions rather than the presence of a single factor alone may adversely affect the respiratory system. For example, in susceptible individuals pulmonary oedema may result from capillary stress failure when performing strenuous exercise in the immersed state, in particular during cold water immersion [11].

\section{Lung function at depth}

Airway resistance is directly proportional to gas density when the flow is laminar. Thus, an increase in density will increase airway resistance accordingly. As higher ambient pressure results in increased gas density, the extent to which flow in large airways is turbulent will increase substantially. It has been shown that when air is used as the breathing gas, maximum breathing capacity varies inversely as the square root of the gas density $[12,13]$. This means that at a depth of $30 \mathrm{~m}$, maximum voluntary ventilation is reduced by $\sim 50 \%$ compared to sea-level values.

Although the respiratory reserve meets the increased gas exchange demands of exercise, ventilatory limitations at depth due to increased gas density restricts exercise capacity in the diving environment, more than the capacity of the cardiovascular system. It is important to consider further consequences of the increased work of breathing under water which may lead to decreased alveolar ventilation with consequent hypercarbia. This hypoventilation is aggravated by poor gas mixing in the lung because of low diffusivity of gases in the dense environment [14]. 


\section{Short-term effects of diving on lung function}

Pulmonary function testing has been established as a mandatory procedure in the routine medical assessment of fitness to dive, in order to detect conditions that may increase the risk of pulmonary injury as a result of diving. The presence of obstructive or restrictive ventilatory disorders would preclude a candidate from diving [15].

Given the conditions associated with diving and their possible effects on the respiratory system, potentially prolonged effects of diving may accumulate gradually over time. A question of interest was whether pulmonary function would normalise immediately after diving. Therefore, a number of studies investigated pulmonary function following single dives under varying conditions. Notably, many studies involved experimental dives in dry compression chambers to simulate diving exposure under somewhat controlled conditions.

Several studies showed that dry chamber dives using air as a breathing gas did not reveal significant changes in expiratory flows or volumes up to $24 \mathrm{~h}$ after simulated depths of 39-87 m [16-19]. However, a temporary decrease in the diffusion capacity of the lung for carbon monoxide (DLCO) was shown [17], reaching a maximum at 20 min post-dive, which was significantly correlated with venous gas microbubbles detected using Doppler ultrasound. A control condition with the subjects breathing pure oxygen during decompression did not reveal microbubbles or a significant decrease of DLCO, indicating that venous gas microbubbles may account for the change in DLCO after diving. The reduction in diffusion capacity was significantly higher in subjects who had venous gas microbubbles compared to those subjects without [18].

Interestingly, some studies did report changes in spirometric indices after wet scuba dives using air as the breathing gas. While no significant changes in ventilatory flows or volumes were found in healthy subjects after wet dives to $4.5 \mathrm{~m}$ in a pool or $50 \mathrm{~m}$ in a wet hyperbaric chamber [20] at $27^{\circ} \mathrm{C}$, reductions in ventilatory flows and volumes were reported after open-sea bounce dives to $10 \mathrm{~m}$ and $50 \mathrm{~m}$ [21] or dives in cold water [22, 23]. One study in recreational scuba divers [24] reported a significant decrease in forced vital capacity (FVC) after open-sea dives at moderate water temperatures, but spirometry was recorded at different times of day and statistical analysis did not control for multiple comparisons. Thus, effects of submergence and static lung loading, as well as effects of respiratory heat and water loss, may contribute significantly to changes in lung function obtained after single wet scuba dives. A reduction in DLCO was found after wet pool dives to $4.5 \mathrm{~m}$, but not when breathing from scuba equipment nonimmersed at atmospheric pressure [20]. Thus, a reduction of diffusion capacity may also occur at shallow depths, related not to decompression stress, but due to subclinical pulmonary oedema or atelectasis. In addition, DLCO was found to decrease after wet dives at $5 \mathrm{~m}$ depth breathing $100 \%$ oxygen from an oxygen rebreather [25]; this decrease did not occur when subjects breathed oxygen from the same rebreather at $5 \mathrm{~m}$ in a dry hyperbaric chamber. This reduction in diffusion capacity after a wet dive breathing oxygen might indicate atelectasis formation.

Oxygen toxicity can account for changes in lung function after deep saturation dives where subjects are exposed to breathing oxygen at higher than normal partial pressure for prolonged periods of time. After a deep saturation dive to $300 \mathrm{~m}$ with an average time under pressure of 21 days, there was an immediate increase in FVC and peak expiratory flow, but a decrease in DLCO of 9.6\% [26], with only partial recovery after follow-up at 1 month and 1 year. Clinical pulmonary oxygen toxicity in one subject suggested that this caused the reduction of DLCO and that a single deep dive may lead to changes in lung function that persist. Reductions in diffusing capacity after deep saturation dives were subsequently confirmed by several studies [27-31], and it was concluded that decreases in DLCO were more sensitive than FVC changes to indicate early pulmonary oxygen toxicity. Subsequent studies after deep saturation dives were designed to demonstrate the contribution of both hyperoxia and occurrence of venous gas microbubbles to the changes seen in DLCO [30, 31]. Remarkably, clinical signs of pulmonary oxygen toxicity and reductions in DLCO occurred at oxygen partial pressures that were considered to be safe $(<50 \mathrm{kPa})$. There was no reduction in FVC as a result of oxygen toxicity following a dive. On the contrary, a small increase in FVC has been described after some dives [26, 31]. A strong correlation was obtained between the reduction in diffusion capacity of the lung and cumulative hyperoxic exposure [31]. Indeed, no changes in pulmonary function were found after a $240-\mathrm{m}$ saturation dive with a modified dive profile including a reduction in the decompression rate and intermittent reduction of oxygen partial pressure [32]. A slight reduction in forced expiratory flows at lower lung volumes has been obtained after saturation dives, and the decline correlated with cumulative hyperoxic exposure [31]. In conclusion, changes in pulmonary function after single deep saturation dives may result from counteracting mechanisms on static and dynamic lung volumes and pulmonary gas exchange $[31,33]$. Training of the respiratory muscles due to increased gas density at depth, oxygen toxicity and decompression stress all contribute to these changes. While most of the pulmonary function changes were temporary in nature, only partial recovery was seen in some changes, such as reductions in DLCO after deep saturation dives. 


\section{Long-term effects of diving on lung function}

The possibility of adverse long-term effects of diving on the respiratory system has been a concern in the health surveillance of commercial divers, in particular since persistent changes in lung function have been obtained after single deep saturation dives.

\section{Cross-sectional studies}

First evidence of persistent lung function changes in divers came from early cross-sectional studies in commercial divers employed by companies operating in the North Sea [34]. FVC was found to be on average $20 \%$ higher than predicted, and forced expired volume in $1 \mathrm{~s}$ (FEV1) was $17 \%$ above predicted; a high FVC appeared to be associated with deepest diving depth. The authors speculated that diving training contributed to large FVCs since divers had an average experience of 7.1 years and had been working at depths up to $340 \mathrm{~m}$. A subsequent publication from the same group of authors [35] reported that the FEV1/FVC ratio in these divers decreased as FVC increased above $100 \%$ predicted and confirmed a positive correlation between FVC and years of diving. A subgroup of divers had low FEV1/FVC ratios and reduction of end-expiratory flows that were interpreted as an indication of obstructive airway changes. An alternative explanation suggested was that large vital capacity is a selection factor for the occupation of diving [36]. A cross-sectional comparison of lung volumes between Royal Navy divers and submariners confirmed larger FVCs in divers, but did not find an association with indices of diving exposure [37]. Accordingly, a study in US Navy divers [38] showed higher than predicted FVC (12.2\%) and FEV1 values $4.3 \%$ below predicted with no relationship between years of diving and lung function variables. Another large cross-sectional study using a registry database of 858 commercial divers and including 132 asymptomatic control subjects [39] revealed a positive association of maximal depth with FVC and negative association with FEV1/FVC ratio. A morphometric study [40] of divers' lungs found a correlation between the increases in FVC measured annually during routine examinations and increased mean alveolar cord length, which in turn reflects alveolar volume. The authors suggested that distension of the alveoli may cause narrowing of small airways. A large cross-sectional controlled study of pulmonary function in British and Norwegian commercial saturation divers [41] showed significantly lower forced expiratory flows and FEV1 compared to matched control subjects, while closing volume was significantly higher. Importantly, cumulative time in saturation was negatively related to expiratory flows and FEV1. These findings were taken as evidence to suggest development of small airways disease in divers. Subsequent cross-sectional studies in German Navy scuba divers [42] confirmed a pattern of reduced expiratory flow rates at low lung volumes when compared to non-diving controls, and mid-expiratory flows at $25 \%$ and $50 \%$ of vital capacity were inversely related to years of diving. However, different group characteristics and selection effects may have confounded the results [43]. In a smaller controlled study on German Navy and commercial construction divers [44], high resolution computed tomography of the chest showed minor lobular air trapping without differences between groups and no relevant abnormalities of small or large airways. A large cross-sectional study in Israeli Navy military divers [45] reported that in those with large lungs, i.e. FVC $>100 \%$ and $\mathrm{FEV} 1 \geqslant 90 \%$ pred, FVC was not different between experienced and inexperienced divers, but forced expiratory flow at $50 \%$ of vital capacity was significantly reduced in the most experienced group. No differences were seen in DLCO. Of note, the 109 divers included in analysis were all nonsmokers. In a random sample of 151 professional divers registered with the Health and Safety Executive in the UK, there was little difference in lung function between divers and 102 offshore workers: after adjusting for smoking only forced expiratory flows at low lung volumes were significantly smaller in the divers [46]. Of note, the majority of divers had decompression diving experience and $\sim 40 \%$ had performed saturation diving. A number of smaller cross-sectional studies in Norwegian commercial construction divers and Croatian and Polish military divers [47-49] were consistent with a pattern of high FVC, normal FEV1 and somewhat reduced mid-expiratory flows.

One early controlled study investigated a larger group of Egyptian special forces divers who were using scuba rebreathers with pure oxygen twice weekly for 90 min over a range of 2-10 years [50]. No differences in ventilatory flows or volumes and DLCO were found. A few cross-sectional studies on recreational scuba divers include a large controlled study of children and 32 adult scuba divers [51] with no significant differences between diving groups and respective controls for all ventilatory flows and volumes as well as DLCO. In another study of older recreational divers [52], mean age 52 years, ventilatory volumes were slightly higher and expiratory flows at low vital capacities slightly lower than predicted. However, all parameters were well within the normal range of variability [53].

\section{Longitudinal studies}

An international consensus conference in 1993 [3] concluded that diving has slight but definite long-term effects on the lung. The scientific evidence was predominantly derived from studies of subacute changes in pulmonary function after deep experimental dives as well as cross-sectional studies from commercial divers. 
Therefore, the evidence was considered limited and future research was recommended, with the highest priority given to longitudinal studies. Subsequently, a number of longitudinal studies have been conducted in commercial and military divers, while long-term follow-up of recreational scuba divers is scarce.

Table 2 lists all longitudinal studies on pulmonary function testing in divers that have been retrieved from searching the Medline/PubMed database from 1946 to December 31, 2016 (cut-off date). Including the three search terms "lung" or "pulmonary", plus "physiology" or "function" plus "diving" revealed 799 hits. 17 publications provided data on 12 longitudinal cohort studies [54, 56, 58-70] and two studies that reported pulmonary function long-term follow-up testing after single deep dives [55, 57]. Studies were heterogeneous in regards to their methodology, study populations, observation period and outcomes.

Early studies in commercial saturation divers indicated an accelerated loss of FVC over time that was associated with diving exposure [54]. In a prospective follow-up of pulmonary function after a deep saturation dive, a decrease in $\mathrm{FEV}_{1}$ was measured that was higher than normal, and was prominent after 1 year [55]. While a decrease in diffusion capacity after deep dives was found to recover during follow-up at 1 and 3 years, a reduction in flows at small lung volumes did not [57]. A prospective study of professional divers that were followed from the beginning of their diving career revealed annual reductions in both FVC and FEV1 that were greater than those obtained from matched police controls [59]. In addition, there was a greater reduction in expiratory flows at low lung volumes, as well as in DLCO. Regression analysis showed a significant relation between loss of lung function and indices of diving exposure. Thus, it appeared that diving contributed to the observed changes in lung function. It is noteworthy that the reduction in FEV 1 of $28.3 \mathrm{~mL}$ annually was within the range expected for healthy normal persons, but the divers started diving young ( $<25$ years), when FEV1 should not decline. In a long-term follow-up of a subset of 37 divers an annual reduction in FEV1 of $40.8 \mathrm{~mL}$ was observed. Although the majority of divers in this cohort were diving on air using scuba or surface supply, a subset was engaged in saturation diving.

In contrast to these results from commercial diving cohorts, more recently a number of studies in military or recreational scuba divers using air or enriched air nitrox reported no accelerated decline in lung function over time. In a study on nitrox divers undertaking astronaut training at shallow depths there was an increase in ventilatory volumes over 3 years. In US Navy scuba divers and German special forces divers using pure oxygen rebreathers there was no change in lung function over time [62, 64]. Likewise, no change was reported from a cohort of recreational scuba divers from France [63]. A large study in German Navy divers [65] could not find an accelerated decline in FEV1 compared to controls. Likewise, a recent large longitudinal cohort study of Royal Netherlands Navy divers showed no change in FEV1 over time [70]. Another study in Singapore Navy divers reported significant increases in ventilatory volumes over time [67]. These results from longitudinal studies do not indicate long-term adverse effects of scuba diving on pulmonary function, and therefore contrast with the results obtained from commercial diving cohorts. Of note, diving exposure in terms of maximum depth and cumulative hours is less extreme in military air scuba divers or recreational scuba divers compared to commercial saturation divers, and decompression dives are performed less frequently. Moreover, possible exposure to toxic gases during underwater work is less likely to be present in military or recreational scuba divers.

\section{Effects of diving on lung function in special populations Paediatrics/adolescents}

With the increasing popularity of recreational scuba diving over the past decades came an increase in the number of children and adolescents participating, which makes up 5-10\% of recreational scuba divers [71]. Data on the effects of diving on the juvenile respiratory system are sparse; only three studies have investigated lung function in children after single scuba dives.

The first study [72] performed spirometry in 18 young divers and 18 controls aged 8-14 years (mean 12.5 years). There were decreases in diving subjects' expiratory flow rates at low lung volumes 10 min after a scuba dive to $3 \mathrm{~m}$ in a swimming pool. FEV1 and peak expiratory flow decreased by $8 \%$ and $5 \%$, respectively; there was no change in FVC. In addition, the authors observed a significant reduction in expiratory flows at low lung volumes. In a controlled cross-sectional study including 14 children aged 8-12 years and 16 adolescents aged 13-18 years, the same group of authors did not find differences in the mean annual changes in lung function over 29 months, but found a significant correlation between the reduction in forced expiratory flows over time and maximal diving depth [63]. Another study [73] investigated lung function in a group of 16 children aged 10-14 years (mean 11.9 years) after open-water scuba dives to depths of $1 \mathrm{~m}$ and $8 \mathrm{~m}$ in a cold lake. There were significant reductions in all spirometric indices after the dives, with mean decreases in FEV1 of $3.8 \%$ and $5.2 \%$ after the $8 \mathrm{~m}$ and $1 \mathrm{~m}$ dives, respectively. Of note, in three subjects the post-dive reductions in FEV1 were $>10 \%$. Another recent study [74] investigated pulmonary function in a larger sample of 41 children aged 8-14 years (mean 11.1 years) after dives in a swimming pool; the diving 
TABLE 2 Overview of longitudinal studies on lung function of divers

\begin{tabular}{|c|c|c|c|c|c|c|}
\hline $\begin{array}{l}\text { First author (year) } \\
\text { [ref.] }\end{array}$ & Design & Diving exposure & Sample size $\mathbf{n}$ & $\begin{array}{l}\text { Age at study } \\
\text { entry years }\end{array}$ & $\begin{array}{l}\text { Study period } \\
\text { years }\end{array}$ & Results \\
\hline Davey (1984) [39] & $\begin{array}{l}\text { Retrospective } \\
\text { registry } \\
\text { database, } \\
\text { controlled }\end{array}$ & $\begin{array}{l}\text { Commercial } \\
\text { divers, including } \\
\text { saturation divers }\end{array}$ & 255 & 28.2 & $>5$ & $\begin{array}{l}\text { Change in FVC significantly } \\
\text { correlated with change in } \\
\text { maximal diving depth }\end{array}$ \\
\hline WATT $_{\text {(1985) }}[54]$ & $\begin{array}{l}\text { Retrospective } \\
\text { cohort }\end{array}$ & $\begin{array}{l}\text { Commercial } \\
\text { divers, including } \\
\text { saturation divers }\end{array}$ & 347 & $\begin{array}{l}30(n=224) \\
33(n=123)\end{array}$ & $\begin{array}{l}3-4(n=224) \\
>5(n=123)\end{array}$ & $\begin{array}{l}\text { Significant decrease in FVC of } \\
240 \mathrm{~mL} \text { ( } \mathrm{n}=224 \text { ) and } 400 \mathrm{~mL} \\
\text { (n123); no correlation with } \\
\text { diving indices }\end{array}$ \\
\hline THORSEN (1993) [55] & $\begin{array}{c}\text { Prospective } \\
\text { follow-up after } \\
\text { single deep dive }\end{array}$ & $\begin{array}{l}\text { Saturation divers, } \\
\text { controls }\end{array}$ & 24 & 30.3 & 3 & $\begin{array}{l}\text { Significant reduction in FEV1 of } \\
210 \mathrm{~mL} \text { after } 1 \text { year and } \\
81 \mathrm{~mL} \cdot y e a r^{-1} \text { over } 3 \text { years; } \\
\text { similar reduction in forced } \\
\text { expiratory flows at low lung } \\
\text { volumes }\end{array}$ \\
\hline THORSEN (1995) [57] & $\begin{array}{l}\text { Prospective } \\
\text { follow-up after } \\
\text { single deep dive }\end{array}$ & Saturation divers & 8 & 24 & 3 & $\begin{array}{l}\text { Significant reduction in } \\
\text { maximal expiratory flows at low } \\
\text { lung volume }\end{array}$ \\
\hline BERMON (1997) [58] & $\begin{array}{l}\text { Retrospective } \\
\text { cohort }\end{array}$ & $\begin{array}{l}\text { Firemen divers } \\
\text { using air scuba }\end{array}$ & 15 & 33.4 & 6 & Significant reduction in $D\llcorner c 0$ \\
\hline SKogstad (2000) [59] & $\begin{array}{l}\text { Prospective } \\
\text { cohort }\end{array}$ & $\begin{array}{l}\text { Professional } \\
\text { scuba divers }\end{array}$ & 87 & 25.2 & 3 & $\begin{array}{l}\text { Significant reduction in FEV } 1 \text { of } \\
1.8 \%(100 \mathrm{~mL}) \text { and of forced } \\
\text { expiratory flows at low lung } \\
\text { volume }\end{array}$ \\
\hline SKOGStAD (2002) [60] & $\begin{array}{l}\text { Prospective } \\
\text { cohort, } \\
\text { policemen } \\
\text { controls }\end{array}$ & $\begin{array}{l}\text { Professional } \\
\text { scuba divers, } \\
\text { including } \\
\text { saturation divers }\end{array}$ & 77 & 24.9 & 6 & $\begin{array}{l}\text { Significantly higher annual } \\
\text { reduction in FVC and FEV } 1 \text { than } \\
\text { in controls; reduction in } \\
\text { maximal expiratory flow rates } \\
\text { at low lung volumes correlated } \\
\text { with cumulative dives }\end{array}$ \\
\hline Lemaitre (2004) [63] & $\begin{array}{l}\text { Prospective } \\
\text { cohort }\end{array}$ & $\begin{array}{l}\text { Recreational } \\
\text { scuba divers }\end{array}$ & 18 & 31.8 & 2.4 & $\begin{array}{l}\text { No significant changes in lung } \\
\text { function }\end{array}$ \\
\hline TetzlafF (2005) [64] & $\begin{array}{l}\text { Prospective } \\
\text { cohort }\end{array}$ & $\begin{array}{l}\text { German special } \\
\text { forces divers }\end{array}$ & 39 & 28.4 & 5.8 & $\begin{array}{l}\text { No significant changes in lung } \\
\text { function }\end{array}$ \\
\hline TetzlafF (2006) [65] & $\begin{array}{l}\text { Prospective } \\
\text { cohort, } \\
\text { submariner } \\
\text { controls }\end{array}$ & $\begin{array}{l}\text { German Navy } \\
\text { divers }\end{array}$ & 468 & 32 & $1-9$ & $\begin{array}{l}\text { No significant difference in } \\
\text { decline of } F E V_{1} \text { between divers } \\
\text { and controls }\end{array}$ \\
\hline SKOGSTAD (2008) [66] & $\begin{array}{l}\text { Retrospective } \\
\text { cohort }\end{array}$ & $\begin{array}{l}\text { Singapore Navy } \\
\text { divers }\end{array}$ & 116 & 31.3 & 5 & $\begin{array}{c}\text { Significant increase in } \mathrm{FVC} \text { and } \\
\mathrm{FEV}_{1}\end{array}$ \\
\hline Chong (2008) [67] & $\begin{array}{l}\text { Prospective } \\
\text { cohort }\end{array}$ & $\begin{array}{l}\text { Professional } \\
\text { scuba divers, }\end{array}$ & 37 & 24.6 & 12 & $\begin{array}{l}\text { Significant reduction in } \\
\text { expiratory flows and volumes }\end{array}$ \\
\hline Sames (2009) [68] & $\begin{array}{l}\text { Retrospective } \\
\text { cohort }\end{array}$ & $\begin{array}{l}\text { New Zealand } \\
\text { occupational } \\
\text { divers }\end{array}$ & 336 & 35.6 & 5.6 & $\begin{array}{l}\text { Significant change in FEV } 1 \% \\
\text { predicted and PEF }\end{array}$ \\
\hline Pougnet (2013) [69] & $\begin{array}{l}\text { Retrospective } \\
\text { cohort }\end{array}$ & $\begin{array}{l}\text { French } \\
\text { professional } \\
\text { divers }\end{array}$ & 33 & 42 & $5-10$ & $\begin{array}{l}\text { Significant decreases in forced } \\
\text { expiratory flows at low lung } \\
\text { volumes, } F E V_{1} / F V C \text { and } D\llcorner c 0\end{array}$ \\
\hline Voortman (2016) [70] & $\begin{array}{l}\text { Retrospective } \\
\text { cohort }\end{array}$ & $\begin{array}{l}\text { Royal } \\
\text { Netherlands } \\
\text { Navy divers }\end{array}$ & 1260 & 26.2 & $>1->16$ & $\begin{array}{c}\text { No significant change in } \mathrm{FEV}_{1} \\
\text { over time (decline of } \\
7 \mathrm{~mL} \cdot \text { year }^{-1} \text { ) }\end{array}$ \\
\hline
\end{tabular}

Data are presented as mean or range, unless otherwise stated. FVC: forced vital capacity; FEV1: forced expiratory volume in $1 \mathrm{~s}$; DLCO: diffusing capacity of the lung for carbon monoxide; PEF: peak expiratory flow. 
depth varied from 3 to $10 \mathrm{~m}$, according to the subjects' age. There were significant reductions in FEV1 and forced expiratory flows at low lung volumes, but not in FVC and residual volume. However, in five children the decrease in FEV1 exceeded $12 \%$. In conclusion, all available data unanimously point at a reduction of expiratory flows and volumes after even shallow water scuba dives in paediatric and adolescent divers. However, the mean changes, although being statistically significant, were within the variability of the measurements. In individual subjects there were clinically meaningful deteriorations in lung function, which is concerning given the risk of serious diving-related injury.

\section{Atopic/asthmatic subjects}

Asthma has been a concern in the assessment of fitness to dive since it may be associated with an increased risk of serious diving-related injury [75, 76]. Thus, due to obvious ethical reasons, only few studies have investigated the effects of diving on pulmonary function in asthmatics.

Immersion reduced ventilatory volumes in 12 subjects with mild exercise-induced asthma and 11 healthy controls. After exercise, there was a significant deterioration of FEV1 and forced expiratory flow at 25-75\% of FVC in the asthmatic subjects compared to both the post-exercise dry control condition and healthy control subjects [77]. In a study comparing changes in pulmonary function after a simulated wet chamber dive to $50 \mathrm{~m}$ between nine subjects with hay fever and nine healthy controls there were slight reductions in FVC $24 \mathrm{~h}$ after the dive and a reduction in specific airway conductance in the atopic subjects only [78], which was interpreted as an increased susceptibility of atopic subjects to diving exposure. Another study investigated pulmonary function in 15 atopic nonasthmatic subjects and 15 healthy controls after dry chamber dives to simulated $50 \mathrm{~m}$ depth and wet dives to $50 \mathrm{~m}$ in seawater [79]. There were slight but statistically significant reductions in FVC after the dry-chamber dive in both groups, while FVC decreased significantly after the wet dive only in controls. FEV1 did not change in either group or condition. However, atopic subjects responded with a worsening of FEV1 after methacholine challenge 20 min after both diving conditions, while controls did not. This reduction in lung function returned to baseline $24 \mathrm{~h}$ after the dives; thus, the authors concluded that scuba diving is associated with early worsening of airway responsiveness to methacholine. One study investigated pulmonary function in asthmatics after scuba dives [80]. Spirometry was performed before and after a $5 \mathrm{~m}$ pool dive at $25^{\circ} \mathrm{C}$ in 22 divers with asthma and 15 healthy controls. Significant post-dive reductions in FEV1 and forced expiratory flows were found in the asthmatics, but not in controls. While this study indicates a trend of airway narrowing in susceptible individuals who may not have good control of their asthma after shallow water scuba dives, the changes were mostly small. Only very few study subjects (four out of 22) [80] had persistent asthma and took regular medication, so no definite conclusions on the effects of scuba diving on patients with current asthma in general can be made.

\section{Summary}

An increase in FVC above $100 \%$ pred has been an unequivocal finding from studies on lung function in divers. This phenomenon may be attributed to repeated exposure to breathing dense gas at depth, i.e. a training effect on the respiratory muscles. However, a correlation between large FVC and indices of diving experience was only inconsistently obtained. Thus, a natural selection for professional divers could be an alternative explanation. Several cross-sectional studies have shown that divers frequently have unusually large lung volumes and a lower FEV1/FVC ratio suggestive of obstructive airways disease or airflow limitation. As FVC appears to be increased in some divers out of proportion to FEV1, the usual accepted ratio of $\mathrm{FEV} 1 / \mathrm{FVC}$ becomes unreliable, and may represent either a training effect, or selection bias, perhaps related to pulmonary dysanapsis, where lung volumes are larger than predicted, while the airway flow is within the normal predicted range [81].

An accelerated loss of lung function related to diving exposure has been reported in commercial divers. This may be due to continued exposure of the lungs and airways to hyperoxia and decompression stress. While most of the described changes in pulmonary function after experimental deep dives were temporary in nature, only partial recovery was seen for some changes; thus indicating subclinical airway and lung inflammation or vascular changes. These pathological changes may result in the development of small airways disease in divers. However, more recent longitudinal data from studies in military or recreational scuba divers could not confirm an accelerated loss of FEV1 or of expiratory flows at low lung volumes over time. Although changes in pulmonary function after single scuba dives have been found to be associated with immersion, ambient cold temperatures and decompression stress, the post-dive changes in lung function were small and transient, and suggested a low likelihood of clinical significance. The published studies in general have small numbers of subjects and are relatively underpowered, and while some statistically significant results are observed, technique and computation of the lung function data are sometimes inappropriate and inconsistent [82]. 
It is concluded that the impact of diving on pulmonary function largely depends on factors associated with the individual diving exposure. However, in susceptible subjects clinically relevant worsening of lung function may occur even after single shallow water scuba dives. Future prospective studies could address the common problems in this field which include inadequate statistical power, heterogeneous subject populations and varied exposures, while the difficulties of performing such studies has to be acknowledged, and better funding would lead to the publication of more good-quality studies.

\section{References}

Bove AA. Diving medicine. Am J Respir Crit Care Med 2014; 189: 1479-1486.

Segadal K, Gulsvik A, Nicolaysen G. Respiratory changes with deep diving. Eur Respir J 1990; 3: 101-108. Hope A, Lund T, Elliott DH, et al. Long Term Health Effects of Diving. An International Consensus Conference. Godøysund June 6-10. Bergen, John Grieg Forlag, 1993.

4 Cotes JE. Respiratory effects of diving. Eur Respir J 1994; 7: 2-3.

5 Fitz-Clarke JR. Mechanics of airway and alveolar collapse in human breath-hold diving. Respir Physiol Neurobiol 2007; 159: 202-210.

6 Thom SR, Milovanova TN, Bogush M, et al. Microparticle production, neutrophil activation, and intravascular bubbles following open-water SCUBA diving. J Appl Physiol 2012; 112: 1268-1278.

7 Agostoni E, Gurtner G, Torri G, et al. Respiratory mechanics during submersion and negative-pressure breathing. J Appl Physiol 1966; 21: 251-258.

8 Dahlbäck GO, Jönnson E, Linér MH. Influence of hydrostatic compression of the chest and intrathoracic blood pooling on static lung mechanics during head-out immersion. Undersea Biomed Res 1978; 5: 71-85.

9 Guyatt AR, Newman F, Cinkotai FF, et al. Pulmonary diffusing capacity in man during immersion in water. J Appl Physiol 1965; 20: 878-881.

10 Tipton MJ. Environmental extremes: origins, consequences and amelioration in humans. Exp Physiol 2016 ; 101 : 1-14.

11 Adir Y, Bove AA. Lung injury related to extreme environments. Eur Respir Rev 2014; 23: 416-426.

12 Maio DA, Farhi LE. Effect of gas density on mechanics of breathing. J Appl Physiol 1967; 23: 687-693.

13 Wood LDH, Bryan AC. Effect of increased ambient pressure on flow-volume curve of the lung. J Appl Physiol 1969; 27: 4-8.

14 Van Liew HD. Mechanical and physical factors in lung function during work in dense environments. Undersea Biomed Res 1983; 10: 255-264.

15 British Thoracic Society Fitness to Dive Group, a Subgroup of the British Thoracic Society Standards of Care Committee. British Thoracic Society guidelines on respiratory aspects of fitness for diving. Thorax 2003; 58 : 3-13.

16 Catron PW, Bertoncini J, Layton RP, et al. Respiratory mechanics in men following a deep air dive. J Appl Physiol 1986; 61: 734-740.

17 Dujić Z, Eterović D, Denoble P, et al. Effect of a single air dive on pulmonary diffusing capacity in professional divers. J Appl Physiol 1993; 74: 55-61.

18 Thorsen E, Risberg J, Segadal K, et al. Effects of venous gas microemboli on pulmonary gas transfer function. Undersea Hyperb Med 1995; 22: 347-353.

19 Tetzlaff K, Staschen CM, Koch A, et al. Respiratory pattern after wet and dry chamber dives to $0.6 \mathrm{MPa}$ ambient pressure in healthy males. Respir Physiol 1999; 118: 219-226.

20 Koehle MS, Hodges ANH, Lynn BM, et al. Diffusing capacity and spirometry following a 60-minute dive to 4.5 meters. Undersea Hyperb Med 2006; 33: 109-118.

21 Skogstad M, Thorsen E, Haldorsen T, et al. Divers' pulmonary function after open-sea bounce dives to 10 and 50 meters. Undersea Hyperb Med 1996; 23: 71-75.

22 Tetzlaff K, Friege L, Koch A, et al. Effects of ambient cold and depth on lung function in humans after a single scuba dive. Eur J Appl Physiol 2001; 85: 125-129.

23 Uhlig F, Muth CM, Tetzlaff K, et al. Lung function after cold-water dives with a standard scuba regulator or full-face-mask during wintertime. Diving Hyperb Med 2014; 44: 70-73.

24 Wilson A. Prevalence and characteristics of lung function changes in recreational scuba divers. Prim Care Respir J 2011; 20: 59-63.

25 van Ooij PJ, van Hulst RA, Houtkooper A, et al. Differences in spirometry and diffusing capacity after a 3-h wet or dry oxygen dive with a $\mathrm{PO}_{2}$ of $150 \mathrm{kPa}$. Clin Physiol Funct Imaging 2011; 31: 405-410.

26 Cotes JE, Davey IS, Reed JW, et al. Respiratory effects of a single saturation dive to $300 \mathrm{~m}$. Br J Ind Med 1987; 44: 76-82.

27 Suzuki S, Ikeda T, Hashimoto A. Decrease in the single-breath diffusing capacity after saturation dives. Undersea Biomed Res 1991; 18: 103-109.

28 Thorsen E, Segadal K, Myrseth E, et al. Pulmonary mechanical function and diffusion capacity after deep saturation dives. Br J Ind Med 1990; 47: 242-247.

29 Thorsen E, Hjelle J, Segadal K, et al. Exercise tolerance and pulmonary gas exchange after deep saturation dives. J Appl Physiol 1990; 68: 1809-1814.

30 Thorsen E, Segadal K, Reed JW, et al. Contribution of hyperoxia to reduced pulmonary function after deep saturation dives. J Appl Physiol 1993; 75: 657-662.

31 Thorsen E, Segadal K, Kambestad BK. Mechanisms of reduced pulmonary function after a saturation dive. Eur Respir J 1994; 7: 4-10.

32 Thorsen E, Segadal K, Stuhr LEB, et al. No changes in lung function after a saturation dive to $2.5 \mathrm{MPa}$ with intermittent reduction in $\mathrm{PO}_{2}$ during decompression. Eur J Appl Physiol 2006; 98: 270-275.

33 Lehnigk B, Jörres RA, Elliott DH, et al. Effects of a single saturation dive on lung function and exercise performance. Int Arch Occup Environ Health 1997; 69: 201-208.

34 Crosbie WA, Clarke MB, Cox RAF, et al. Physical characteristics and ventilatory function of 404 commercial divers working in the North Sea. Br J Ind Med 1977; 34: 19-25.

35 Crosbie WA, Reed JW, Clarke MC. Functional characteristics of the large lungs found in commercial divers. J Appl Physiol Respir Environ Exerc Physiol 1979; 46: 639-645. 
55 Thorsen E, Segadal K, Kambestad BK, et al. Pulmonary function one and four years after a deep saturation dive. Scand J Work Environ Health 1993; 19: 115-120.

56 Bermon S, Lapoussière JM, Dolisi C, et al. Pulmonary function of a firemen-diver population: a longitudinal study. Eur J Appl Physiol Occup Physiol 1994; 69: 456-460.

57 Thorsen E, Kambestad BK. Persistent small-airways dysfunction after exposure to hyperoxia. J Appl Physiol 1995; 78: 1421-1424.

58 Bermon S, Magnié MN, Dolisi C, et al. Decreased pulmonary diffusing capacity of divers over a 6-year period. Eur J Appl Physiol Occup Physiol 1997; 76: 170-173.

59 Skogstad M, Thorsen E, Haldorsen T. Lung function over the first 3 years of a professional diving career. Occup Environ Med 2000; 57: 390-395.

60 Skogstad M, Thorsen E, Haldorsen $\mathrm{T}$, et al. Lung function over six years among professional divers. Occup Environ Med 2002; 59: 629-633.

61 Fitzpatrick DT, Conkin J. Improved pulmonary function in working divers breathing nitrox at shallow depths. Aviat Space Environ Med 2003; 74: 763-767.

62 Shykoff BE, Petryszyn JD. Stability of pulmonary function in U.S. Navy divers. Undersea Hyperb Med 2004; 31: 385-386.

63 Lemaître F, Bedu M, Coudert J. Pulmonary function in children and adult scuba divers: a longitudinal study. Pediatric Exerc Sci 2004; 16: 378-390.

64 Tetzlaff K, Friege L, Theysohn J, et al. Lung function in military oxygen divers: a longitudinal study. Aviat Space Environ Med 2005; 76: 974-977.

65 Tetzlaff K, Theysohn J, Stahl C, et al. Decline of FEV1 in scuba divers. Chest 2006; 130: 238-243.

66 Skogstad M, Skare Ø. Pulmonary function among professional divers over 12 years and the effect of total number of dives. Aviat Space Environ Med 2008; 79: 883-887.

67 Chong SJ, Tan TW, Lim JYJ. Changes in lung function in Republic of Singapore Navy divers. Diving Hyperb Med 2008; 38: 68-70.

68 Sames C, Gorman DF, Mitchell SJ, et al. The long-term effects of compressed gas diving on lung function in New Zealand occupational divers: a retrospective analysis. Diving Hyperb Med 2009; 39: 133-137.

69 Pougnet R, Henckes A, Mialon P, et al. Evolution of the ventilator function of professional divers over 10 years. Undersea Hyperb Med 2013; 40: 339-343.

70 Voortman M, van Ooij PJAM, van Hulst RA, et al. Pulmonary function changes in Navy divers during their professional careers. Undersea Hyperb Med 2016; 43: 649-657.

71 Winkler BE, Muth CM, Tetzlaff $\mathrm{K}$. Should children dive with self-contained underwater breathing apparatus (SCUBA)? Acta Pediatr 2012; 101: 472-478.

72 Lemaitre F, Tourny-Chollet C, Hamidouche V, et al. Pulmonary function in children after a single scuba dive. Int J Sports Med 2006; 27: 870-874.

73 Winkler BE, Tetzlaff K, Muth CM, et al. Pulmonary function in children after open water SCUBA dives. Int $J$ Sports Med 2010; 31: 724-730.

74 Wollin P, Christmann M, Kroker A, et al. Lungenfunktionsmessung bei Kindern vor und nach einem altersadaptierten SCUBA Tauchgang im Schwimmbad. [Lung function testing in children before and after an age-adapted SCUBA dive in a swimming pool]. Pneumologie 2011; 65: 308-313. 
75 Tetzlaff K, Muth CM, Waldhauser LK. A review of asthma and scuba diving. J Asthma 2002; 39: 557-566.

76 Adir Y, Bove AA. Can asthmatic subjects dive? Eur Respir Rev 2016; 25: 214-220.

77 Leddy JJ, Roberts A, Moalem J, et al. Effects of water immersion on pulmonary function in asthmatics. Undersea Hyperb Med 2001; 28: 75-82.

78 Tetzlaff K, Staschen CM, Struck N, et al. Respiratory effects of a single dive to 50 meters in sport divers with asymptomatic respiratory atopy. Int J Sports Med 2001; 22: 85-89.

79 Cirillo I, Vizzaccaro A, Crimi E. Airway reactivity and diving in healthy and atopic subjects. Med Sci Sports Exerc 2003; 35: 1493-1498.

80 Ivkovic D, Markovic M, Todorovic BS, et al. Effect of a single pool dive on pulmonary function in asthmatic and non-asthmatic divers. Diving Hyperb Med 2012; 42: 72-77.

81 Ong LM, Bennett MH, Thomas PS. Pulmonary dysanapsis and diving assessments. Undersea Hyperb Med 2009; 36: $375-380$.

82 Neuman TS, Clausen JL. Recommend caution in defining risk factors for pulmonary barotrauma in divers. Chest 1998; 114: 1791-1792. 